\title{
A comparative evaluation of models of whole rumen function
}

\author{
J Dijkstra*, J France \\ Institute of Grassland and Environmental Research, North Wyke Research Station, Okehampton, \\ Devon EX2O 2SB, United Kingdom; "Present address: Wageningen Agricultural University, \\ Department of Animal Nutrition, PO Box 338,6700 AH Wageningen, the Netherlands
}

\begin{abstract}
Summary - A review is presented on the representation of various rumen fermentation aspects in whole rumen function models in relation to current knowledge on these processes, and areas in need of improved representation are highlighted. The importance of adequately stating the objective of the model in relation to the level of representation of rumen processes is stressed. No model yet exists which can accurately simulate rumen metabolism in all circumstances. A number of issues related to rumen modelling require further research. The sound representation of rumen microbial metabolism is essential. Aspects of microbial metabolism which deserve further attention include microbial distribution within the rumen, microbial interactions, and chemical composition of microbial matter. The representation of outflow from the rumen requires a more mechanistic approach, which should adequately cover continuous as well as discontinuous feeding regimes. Finally, the representation of VFA production is identified as being inadequate, and future attempts to improve prediction of VFA profile should include provisions for the effect of amount and rate of substrate degradation and microbial species preferences on type of VFA produced.
\end{abstract}

\section{Introduction}

Grazed and conserved forage and other fibrous feeds are heavily relied upon in ruminant livestock production systems. The amount and type of absorbed nutrients available for production are significantly influenced by processes occurring in the reticulo-rumen. Considerable research on various aspects of rumen fermentation processes has accumulated over time. This research includes in vivo and in vitro research into digestion of ingested nutrients within the rumen, passage out of the rumen of undigested material, metabolism of rumen micro-organisms, and formation of the end products of rumen microbial activity.

As our understanding of the rumen ecosystem has improved, the use of mechanistic modelling as a research tool has increased, and mathematical models of whole rumen function have been developed which integrate knowledge on various aspects of the processes in the rumen. Stimulated by the work of Baldwin et al (1970), several models of whole rumen function have been developed. Nearly all the models have endeavoured to represent the digestion and passage of ingested nutrients, microbial metabolism, and the formation of end products of digestion. However, they have not necessarily shared common objectives. The evaluation of models depends on an appraisal of the total effort in relation to the objectives of the modelling exercise. Detailed information on this topic can be found in textbooks (France and Thornley, 1984; Thornley and Johnson, 1990) and papers presented at modelling symposia (Boston et al, 1995; Dijkstra and France, 1995a; Emmans, 1995). Whole rumen function models have been evaluated in comparison to each other (the champion-challenger approach) by simulating the rumen processes with several diets and comparing the results of each model and the observations (Ramangasoavina et al, 1991; Bannink et al, 1993; Kohn et al, 1995). Whilst such exercises can yield valuable information, particularly for (future) application in the field, the results of these comparisons have to be interpreted very carefully, because of the differences in model objectives. For example, a mathematical model developed with the objective to obtain a better understanding of interactions between microorganisms in the rumen can not easily (nor fruitfully) be compared to a mathematical model developed to predict the type of volatile fatty acids (VFA) formed in the rumen. Besides, a potential difficulty is the proper use of models by researchers, not involved in development of the model. For example, Bannink et al (1993) encountered problems in 
setting a number of input variables because insufficient guidance in the original modelling papers were supplied. In a number of situations, Kohn et al (1995) simulated complete disappearance of fibrolytic microbes using the model of Dijkstra et al (1992), due to an incorrect setting of the fractional rate of passage.

The objective of this paper is to review the representation of various rumen fermentation aspects in whole rumen function models in relation to current knowledge on these processes, and to highlight areas of representation which need further attention. The use of modelling in optimization of rumen processes has been reviewed recently (Sauvant et al, 1995). In this paper, after a brief description of the whole rumen function models developed to date and their objectives, the representation of four elements of the rumen processes will be discussed. These are: degradation of ingested substrates, outflow from the rumen, microbial metabolism, formation of fermentation end products.

\section{Objectives and brief description of whole rumen function models}

Much of the activities to develop mechanistic mathematical models of whole rumen function is owed to the earlier work of Baldwin et al (1970). They attempted to integrate current knowledge on energy and protein metabolism within the rumen in order to predict the formation and utilization of fermentation endproducts in sheep. This model comprises a system of first-order differential equations and all the fluxes represented are assumed to obey mass-action kinetics. These efforts were obviously limited by availability of both research data and computer power, but model behaviour relating to the yield of VFA, methane, and microbes for a range of forage based diets appeared to be realistic. This work identified several areas where knowledge was inadequate, and stimulated in particular further research into utilization of ammonia and amino acids by microbes (Maeng et al, 1976).

Reichl and Baldwin (1975) developed a model to evaluate competitive relationships among rumen microbial groups as affected by protein and carbohydrate availability. The rumen fermentative processes are in the form of linear equations and solved by linear programming techniques, in which the objective function consists of the relative metabolic activities of the eight microbial groups. Considerable simplifications of the rumen microbial groups had to be made though when solving the model, and in their evaluation Reichl and Baldwin (1976) concluded that the concepts represented in the model were not sufficient.

In contrast to the previous efforts, in another model of rumen processes in sheep Baldwin et al (1977) chose to represent the microbial population as a single entity. The objectives of this model were to permit identification of specific aspects of rumen function where current knowledge was inadequate, and to test hypotheses regarding factors likely to affect nutritive value. The representation of the nitrogen $(\mathrm{N})$ transactions in the rumen are very similar to the $\mathrm{N}$ digestion model developed by Mazanov and Nolan (1976) and a total of twelve state variables are included in this model. The simulation results stimulated further experimental research into VFA stoichiometric relationships and rumination patterns (Murphy et al, 1982, 1983). An update of the Baldwin et al (1977) model was described by Murphy et al (1986) and includes more extensive representation of fibre present in particles of different size and of the dynamic aspects of VFA metabolism in the rumen.

Black et al (1981) judged the previously mentioned rumen models too complex and detailed to be readily compatible with an existing sheep growth model. They developed a model of rumen fermentation with the objective to predict the flow of nutrients from the stomach and in particular, total amino acid $N$. Some processes are represented using existing empirical equations, whilst a number of microbial aspects are represented in a mechanistic way. Black et al (1981) acknowledged that integration of the difference equations which constitute their model was not satisfactory from a mathematical point of view, and suggested that the model structure could be improved by conforming to the standard rate:state formalism. The model was evaluated by Beever et al (1981), in particular on its simulation of protein flow out of the rumen in comparison to in vivo data. The model did not always provide adequate predictions and was considered, like Baldwin's efforts, to be of more value as a research tool. 
France et al (1982) promoted a mathematical refinement of the previous model based on the rate:state formalism, attempting to provide a mechanistic description and quantitative understanding of the main processes occurring in the rumen of sheep. A series of differential equations describe the system of nine state variables. For the first time, pulsed dietary inputs were compared with observations. In continuous mode, model behaviour was satisfactory, but considerable discrepancies were found between experimental data and the pulsed model output. This model does not include representation of the VFA produced in the rumen.

Baldwin et al (1987b) were the first to develop a model of rumen function in dairy cattle. Their objective was to predict the rate and pattern of nutrient absorption in the dairy cow. This model is mathematically based on previous efforts of France et al (1982), and contains a more comprehensive description of the chemical and physical characteristics of the diet as well as a representation of VFA formation. The model has 12 major state variables, plus a representation of the distribution of large and small particles and water. Fluxes are given either MichaelisMenten or mass-action forms. Evaluation against in vivo data in high producing dairy cattle was satisfactory for most diets, apart from the VFA yields. Also, on high concentrate diets model performance with respect to nutrient digestion was less satisfactory. Some of the suggestions to improve the model, viz depressed microbial activity at reduced $\mathrm{pH}$, are addressed in an update of this model (Argyle and Baldwin, 1988).

Following the work of Baldwin et al (1987a, b), Danfær (1990) also addressed the issue of a mechanistic model of dairy cow metabolism, to simulate the digestion and metabolism of nutrients. The rumen part of the model consists of 17 state variables in the rate:state form. Evaluation of the model is not independent, as experimental data used in part to develop the model were subsequently used in evaluation. Also, model parameters were allowed to be fitted mathematically until acceptable agreement was achieved, and some of the parameter values changed remarkably in order to achieve agreement.

The Cornell net carbohydrate and protein system was developed to provide estimates of nutrients (energy and protein) available for absorption in dairy or beef cattle, and is claimed to serve as a research tool as well as to serve in practical ration balancing. It contains a rumen submodel described by Russell et al (1992) and Sniffen et al (1992). This consists of a number of static equations, representing degradation and passage of several feed fractions, and equations to represent growth and outflow of two microbial groups. For the rumen submodel, only bacterial $N$ outflow was evaluated against data obtained with beef and dairy cattle. An update of the rumen submodel contains equations to predict individual amino acid flows and a more extensive evaluation was presented (O'Connor et al, 1993).

Dijkstra et al (1992) built on achievements of Baldwin et al (1987b) primarily by improving microbial dynamics. The objective of their modelling exercise was to examine the effect of supplementation of forage diets on the profile of nutrients available for absorption in cattle. The model consists of 17 state variables and two microbial groups are distinguished. Specific areas of improvement of representation include the combination of microbial substrate preference, differential outflow and microbial composition, and recycling of microbial matter. This model was thoroughly tested on a range of diets and generally provided reasonable predictions, with the main exception of patterns of VFA production (Neal et al, 1992). Besides, it was shown that the representation of protozoal activities needed more attention and this was subsequently addressed in the model of Dijkstra (1994a), in which the objective was to provide a quantitative understanding of protozoal dynamics.

Lescoat and Sauvant (1995) considered none of the existing rumen models to be complete because of lack of consideration of digestive interactions between substrates, and consideration of individual amino acids (although both aspects were actually addressed in a number of models mentioned before). They developed another rumen model to integrate information in order to predict duodenal amino acid flux and VFA production in dairy cattle. The model consists of 22 state variables and virtually all differential equations are in mass action form. The model parameters are derived mainly from data obtained in sheep. The full model is evaluated against data obtained from goats fed a range of diets at 
maintenance level, and the duodenal fluxes of lysine and methionine evaluated using data from beef and dairy cattle. Whilst lysine and methionine fluxes were predicted satisfactorily, large bias was reported for the predicted VFA and ammonia concentration in rumen fluid as well as for the microbial efficiency.

\section{Degradation of ingested substrates}

The rate of degradation of a feed component is the result of its intrinsic properties, the microbial activity, and animal activities such as ruminating. Virtually all whole rumen function models distinguish potentially degradable and undegradable feed components, and the degradable component is often divided into a rumen fluid soluble and insoluble component (Figure 1). The extent of degradation of feed components and hence flow to the duodenum is affected by the balance between degradation and passage out of the rumen; the latter will be discussed in section "Outflow of substrates".

\section{Degradation of structural carbohydrates}

In a number of models (Black et al, 1981; Dijkstra et al, 1992; Dijkstra, 1994a; Lescoat and Sauvant, 1995), the undegradable fraction of the structural carbohydrate (SC) content of a feed is adopted from in vitro or in sacco techniques. The actual in vitro or in sacco estimate of the different fractions and fractional degradation rates can vary according to factors such as the last time measuring point included

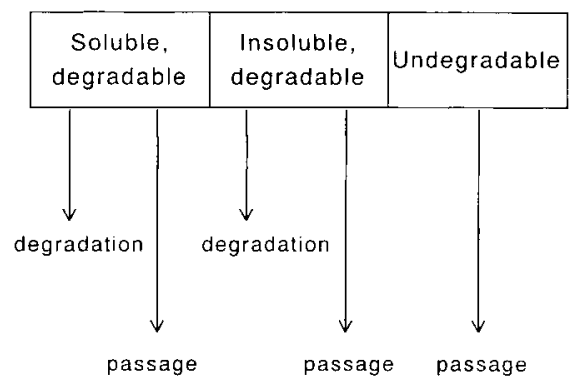

Figure 1. Substrate components commonly distinguished in whole rumen function models.
(Mertens, 1977), the model applied to fit the data (Robinson et al, 1986a), and chemical pretreatment (McAllister et al, 1990). To obtain consistent input data, it is therefore necessary to standardize the in vitro or in situ methods. In the Baldwin et al (1987b) model, all SC are assumed to be potentially degradable and lignin is assumed to be undegradable. However, in sacco data indicate a much higher undegradable NDF fraction than the lignin fraction only (Robinson et al, 1986a). In the Cornell model, the undegradable fibre fraction is estimated as $2.4 \mathrm{x}$ lignin content (Sniffen et al, 1992). However, the relationship between lignin and the undegradable fraction varies between feeds (Robinson et al, 1986a; Chesson, 1988). The fractional degradation rate of the degradable fraction of $S C$ is an input to most models. When sensitivity analyses were performed in these models, this parameter proved to be of key importance in prediction of fibre degradation. The Cornell model (Russell et al, 1992; Sniffen et al, 1992) and the model of Lescoat and Sauvant (1995) assume a first-order degradation process, and the relative extent of degradation is calculated as the fractional degradation rate over the sum of fractional degradation and passage rate. Thus, these two models do not take into account the effect of a low $\mathrm{N}$ availability on degradation of carbohydrates (review Oldham, 1984). All other models assume that degradation is modified by the amount of microbial matter, which in turn is determined by, amongst others, the availability of $N$ containing substrates in rumen fluid. Moreover, the degradation of $\mathrm{SC}$ can be affected by the availability of non-structural carbohydrates (NSC). This aspect requires a distinction to be made in models between microbes degrading the SC and microbes degrading the NSC (explained in section "Microbial metabolism"). An abundance of easily degradable carbohydrates will decrease rumen fluid $\mathrm{pH}$ and might decrease microbial activity and fibre digestibility (review Erdman, 1988). This aspect is represented in the models of Argyle and Baldwin (1988), Dijkstra et al (1992), Dijkstra (1994a) and Lescoat and Sauvant (1995). Strangely enough, in the Cornell model microbial growth yield is reduced when diets contain less than $20 \%$ NDF, to represent the depressing effect of $\mathrm{pH}$ on rumen microbial growth, but no effect on fibre degradation is included (Russell et al, 1992). Besides, in 
contrast with the strategy in which $\mathrm{pH}$ is used to simulate depressive effects, the Cornell approach cannot take into account the effects of feed intake level and of starch degradation characteristics on $\mathrm{pH}$ and fibre degradation, observed in cattle fed diets with almost equal NDF contents (DePeters and Taylor, 1985; McCarthy et al, 1989).

Given the importance of fibre in ruminant diets, it is odd that only a few models have been evaluated against independent observations on fibre outflow. The model of France et al (1982) was evaluated using data from sheep fed grass diets (one experiment, four dietary treatments). The root mean square prediction error (root MSPE; Bibby and Toutenburg, 1977) was $24 \%$ of observed mean when evaluated in the continuous input version of the model, and any bias was not apparent. Neal et al (1992) evaluated the model of Dijkstra et al (1992) on a range of dietary treatments (data from 6 experiments and in total 28 treatments) and the root MSPE was $13 \%$ of observed mean, again without bias. The protozoa model of Dijkstra (1994a) was used to examine the contribution of protozoa to NDF degradation in the rumen of cattle (Dijkstra and Tamminga, 1995). Evaluation of this model against data from dairy cattle at different intake levels (one experiment, five intake levels) showed a root MSPE of $4 \%$ of the observed mean.

The predictions of several models have been compared with each other and with observations. In table I the results (satisfactory prediction or under- or overprediction of nutrient flow) are summarized. Bannink et al (1993) compared the rumen models of Baldwin et al (1987b), Danfær (1990), and Dijkstra et al (1992) using outflow data obtained with dairy cattle fed grass based diets at intermediate intake levels (two experiments with 7 treatments). Kohn et al (1995) compared the models of Baldwin et al (1987b), Dijkstra et al (1992) and the Cornell model (Russell et al, 1992; Sniffen et al, 1992) using observations from five dairy cattle experiments with 20 treatments. For SC outflow in the models of Baldwin et al (1987b) and Dijkstra et al (1992), these comparisons are not in line with each other. The problems in setting the driving variables, as mentioned in the introduction, contribute to the differences between both comparisons. In conclusion, the representation of fibre degradation in the rumen requires accurate model input with respect to degradable and undegradable fractions and fractional degradation and passage rates, as well representation of the effects of microbial activity on fibre breakdown.

\section{Degradation of non-structural carbohydrates}

In most models, the NSC components soluble starch, insoluble starch, and soluble sugars are

Table I. Results of comparison of whole rumen function models.

Whole rumen function model

\begin{tabular}{|c|c|c|c|c|c|c|c|c|}
\hline \multirow{3}{*}{$\begin{array}{l}\text { Duodenal } \\
\text { flow of } 1 \text { : }\end{array}$} & \multicolumn{3}{|c|}{$\begin{array}{l}\text { Baldwin et al } \\
\quad(1987 b)\end{array}$} & \multirow{3}{*}{$\begin{array}{c}\text { Danfær } \\
\text { (1990) } \\
\text { B }\end{array}$} & \multicolumn{2}{|c|}{$\begin{array}{l}\text { Cornell-Russell et al (1992) } \\
\text { Sniffen et al (1992) }\end{array}$} & \multicolumn{2}{|c|}{$\begin{array}{c}\text { Dijkstra et al } \\
\quad(1992)\end{array}$} \\
\hline & - & - & & & $\ldots$ & . & - & - \\
\hline & $A^{2}$ & $\mathrm{~B}^{2}$ & $\mathrm{C}^{2}$ & & A & C & $B$ & C \\
\hline SC & $\mathrm{NA}^{3}$ & $=/+$ & - & - & NA & $=1-$ & - & + \\
\hline Starch & NA & + & NA & $=1-$ & NA & NA & $-1+$ & NA \\
\hline TNAN & $=$ & $=$ & - & - & $=$ & $=1+$ & $=$ & $=1-$ \\
\hline MNAN & - & + & $=1-$ & + & $=1-$ & + & + & - \\
\hline NMNAN & + & - & - & - & $=1+$ & - & $=1-$ & + \\
\hline Lipid & NA & $=$ & NA & + & NA & NA & $=1+$ & NA \\
\hline
\end{tabular}

1 SC, structural carbohydrates; TNAN, total non-ammonia nitrogen; MNAN, microbial non-ammonia nitrogen; NMNAN, non-microbial non-ammonia nitrogen. ${ }^{2}$ Comparison A, 14 experiments with in total 49 dietary treatments; Ramangasoavina et al (1991); Comparison B, 2 experiments with in total 7 dietary treatments; Bannink et al (1993); Comparison C, 5 experiments with in total 20 dietary treatments; Kohn et al (1995). ${ }^{3}$ NA, comparison not available; - , underprediction of flow; $=$, satisfactory prediction of flow; + , overprediction of flow 
distinguished. Generally, the starch component of NSC received much more attention in ruminant nutrition than the sugar component. All models presume that NSC is potentially completely degradable. Like $\mathrm{SC}$, the soluble and insoluble starch component, and the fractional degradation rate of starch, are adopted from in vitro or in sacco studies. The Cornell model (Russell et al, 1992; Sniffen et al, 1992) and the model of Lescoat and Sauvant (1995) assume first-order degradation kinetics, as explained in the previous section, whilst all other models in addition modify degradation according to the microbial mass present. The latter representation is based on observations that the microbial uptake rate of soluble substrates is high, but not unlimited, as indicated by accumulation of soluble sugars immediately after feeding a diet rich in easily degradable NSC (Clapperton and Czerkawski, 1969). The NSC outflow consists of two fractions: feed NSC escaping rumen fermentation, and microbial storage polysaccharides. Thus, the presence of microbial storage polysaccharides can affect the apparent digestibility of NSC in the rumen. The microbial storage polysaccharide content is probably the most variable component of microbial dry matter (review Storm and Ørskov, 1983). Except for the models of Dijkstra et al (1992) and Dijkstra (1994a), all models have assumed a fixed microbial non-protein composition (see section «Microbial metabolism»). The microbial contribution towards NSC outflow can be significant and has been suggested as one of the factors to explain the observed difference between in sacco and in vivo rumen starch escape values (Nocek and Tamminga, 1991).

Evaluation of the simulation of NSC outflow has received slightly more attention than that of SC outflow. Evaluation of the model of France et al (1982) against NSC ( $\alpha$-hexose and water soluble carbohydrates) outflow data showed severe underprediction when not accounted for microbial storage polysaccharide outflow, and severe overprediction when microbial storage polysaccharides were included. The Baldwin et al (1987b) model predictions were compared to data obtained with dairy cattle fed corn or barley based diets (one experiment, four treatments) and a root MSPE of $30 \%$ can be calculated for starch outflow. The starch outflow in the model of Dijkstra et al (1992), when compared with observations from seven experiments and in total 25 treatments (barley, maize, sorghum and tapioca were main sources of starch), was predicted with a root MSPE of $12 \%$ of the observed mean (Dijkstra and France, 1995b). In the comparison of models reported by Bannink et al (1993) (table I), starch outflow was predicted satisfactory on low starch diets (less than 1\% starch in diet DM) only by the model of Danfær (1990), whereas on the other diets, only the models of Baldwin et al (1987b) and Dijkstra et al (1992) resulted in fairly accurate predictions. Bannink et al (1993) judged the approach reported by Dijkstra et al (1992), in which the microbial polysaccharide level varies according to dietary characteristics, of most value for correct predictions of starch outflow.

\section{Degradation of lipids}

The representation of lipid degradation has received only limited attention in rumen models. Generally, feed lipids are rapidly hydrolysed and hydrogenated in the rumen (Harfoot, 1981). The metabolism of the resulting long chain fatty acids (LCFA) by rumen microbes is low, but some LCFA can be taken up by microbes in the rumen (Bauchart et al, 1990). A number of rumen models have no representation of lipid dynamics at all (Baldwin et al, 1970; France et al, 1982; Lescoat and Sauvant, 1995). In other models, the lipid fraction is assumed to be hydrolysed in glycerol (assumed to be degraded at a rate similar to soluble sugar degradation) and LCFA. The models of Baldwin et al (1977), Cornell (Russell et al, 1992; Sniffen et al, 1992), and Dijkstra et al (1992) assume that no LCFA are taken up by microbes, and the total flow of LCFA to the intestine in these models is the total of LCFA arising from feed and from the microbial matter. The models of Danfær (1990) and Baldwin et al (1987b) represent uptake of LCFA by microbes, but in a fixed manner such that in extreme dietary situations (e.g. very low lipid content of the diet), the biologically unrealistic situation can be simulated where more lipid is taken up by microbes than is available from the diet. Uptake of LCFA by microorganisms dependent on its concentration or availability is represented in the models of Black et al (1981) and Dijkstra (1994a). In some rumen modelling papers, the depressive effect of large amounts of LCFA on microbial activity and substrate degradation (see survey Van Nevel and 
Demeyer, 1988) is acknowledged, but this effect is not included in any rumen model. Also, none of the models consider the effects of protection of dietary lipid upon lipid metabolism in the rumen.

Evaluation of lipid digestion in rumen models is hardly reported. From the data reported by Baldwin et al (1987b) a MSPE of $28 \%$ of the observed mean LCFA absorption can be calculated, with approximately half of the error due to bias (underestimation). In the comparison of three models reported by Bannink et al (1993), the model of Baldwin et al (1987b) predicted LCFA outflow satisfactory, whereas the models of Danfær (1990) and, to a lesser extent, of Dijkstra et al (1992) overpredicted LCFA flow (table I). In view of the present concern with the fat content and fat composition of animal products, the current representations will have to be extended in order to examine the profile of LCFA available for absorption.

\section{Degradation of nitrogen containing substrates}

The in sacco kinetics of $\mathrm{N}$ containing substrates have been measured for many feeds. In most models, $\mathrm{N}$-containing substrates distinguished are: undegradable protein; insoluble, degradable protein; soluble protein; ammonia. In most models degradation of feed protein is assumed to be affected by the intrinsic feed properties and the amount of microbial mass present, but there are two exceptions. In the model of Lescoat and Sauvant (1995) a first-order degradation process is assumed. The Cornell model contains a mixture of both approaches; the degradation of feed proteins is a first-order process, but degradation of peptides is modified according to microbial mass present (Russell et al, 1992). In line with experimental results (Russell et al, 1983), most rumen models assume no direct effect of carbohydrates on the rate of protein degradation, whereas the effect of carbohydrate availability on the balance between incorporation of amino acids and peptides into microbial matter, or fermentation to ammonia, is included in all rumen models. Endogenous $\mathrm{N}$ input to the rumen (urea and proteins entering with saliva or through the rumen wall) may be a significant ruminal input when dietary $\mathrm{N}$ levels are low. The model of Lescoat and Sauvant (1995) does not include a representation of endogenous $\mathrm{N}$ input, and this has important consequences for rumen fluid ammonia concentration (see section "Microbial metabolism"). A number of models only represent endogenous urea input with saliva (Baldwin et al, 1977) or both endogenous urea and endogenous protein with saliva (Black et al, 1981; France et al, 1982; Baldwin et al, 1987b). In other models, urea input with saliva and absorption of urea across the rumen wall is represented (Baldwin et al, 1970; Danfær, 1990; Russell et al, 1992). However, in the latter model, no effect of the level of rumen fluid ammonia concentration on microbial growth is represented, and therefore the urea recycling represented does not affect model results at all. The most comprehensive representation includes endogenous urea with saliva and through the rumen wall, as well as endogenous protein with saliva (Dijkstra et al, 1992). The need for a detailed representation on low $\mathrm{N}$ diets was demonstrated in the evaluation of the Black et al (1981) model by Beever et al (1981). The predicted amount of recycled $\mathrm{N}$ with saliva was considerably lower than the total amount of recycled $\mathrm{N}$ observed, and rectification of the predicted amount improved the prediction of total protein flow significantly. Ramangasoavina et al (1991) evaluated the Baldwin et al (1987b) and Cornell (Russell et al, 1992; Sniffen et al, 1992) models with respect to $\mathrm{N}$ outflow, and reached the same conclusion. In the model of Dijkstra et al (1992) the prediction of total nonammonia $N$ (NAN) outflow was satisfactory on diets where duodenal NAN flow exceeded $N$ intake by up to $20 \%$ (Neal et al, 1992) and these results indicate that their representation of $\mathrm{N}$-recycling was adequate.

The total outflow of NAN from the rumen consists of rumen undegraded feed and endogenous NAN and microbial NAN (for evaluation of microbial NAN, see section "Microbial metabolism"). The construction of most models is such that any over- or underprediction of microbial NAN flow will be balanced by under- or overprediction of nonmicrobial NAN flow and the total NAN flow is often predicted with much higher accuracy than its components (Ramangasoavina et al, 1991; Neal et al, 1992). Evaluation of the model of Black et al (1981) using observations from 4 experiments and in total 20 treatments, resulted in a root MSPE of $14 \%$ of the mean 
observed total protein outflow, and as explained before, protein outflow on low $\mathrm{N}$ diets was severely underpredicted. The root MSPE for France et al (1982) model (one experiment, 4 treatments) was $73 \%$ of observed mean total $\mathrm{N}$ outflow and most values were severely overpredicted. The root MSPE was $8 \%$ of observed protein outflow (one experiment, 4 treatments) for the model of Baldwin et al (1987b). Neal et al (1992) evaluated the model of Dijkstra et al (1992) and reported a root MSPE of $13 \%$ of observed total NAN outflow (6 experiments, 20 treatments), but root MSPE for non-microbial NAN outflow was much higher $(58 \%)$. Based on $\mathrm{R}^{2}$ values, the Cornell model predicted NAN outflow with higher accuracy $\left(R^{2}=95 \%\right.$; 21 experiments with in total 56 treatments) than non-microbial NAN outflow $\left(R^{2}=79 \%\right)$ (O'Connor et al, 1993). In the comparison of several models reported by Ramangasoavina et al (1991), Bannink et al (1993) and Kohn et a) (1995), the total NAN flow was often predicted satisfactory, but there is no consistent pattern for microbial and nonmicrobial NAN flow within models between comparisons (table I).

The amino acid (AA) composition of the NAN flow to the duodenum is of interest as well. Two models have included a representation of AA dynamics in the rumen. Lescoat and Sauvant (1995) distinguished four groups of AA: lysine, methionine, branched-chain AA, and the remainder. In an update of the Cornell model, O'Connor et al (1993) represented 9 essential AA. Like NAN flow, the AA flow can be distinguished into microbial $A A$ flow and undegraded feed $A A$ flow. In both models, the AA composition of bacteria is assumed to be constant. However, the AA composition of bacteria (expressed as unit of individual $A A$ per unit total $A A$ ), obtained from 61 dietary treatments was highly variable (review Clark et al, 1992). Also, the AA composition of protozoa differs from that of bacteria (Czerkawski, 1976) and the contribution of protozoal flow to total microbial flow varies with the diet (Cockburn and Williams, 1984). Neither of these two models account for the protozoal contribution. The AA composition of the undegraded feed NAN passing to the duodenum is assumed to be represented by the AA composition of the insoluble dietary protein $\left(O^{\prime}\right.$ Connor et al, 1993), on the assumption that the rumen degradability of soluble protein is much higher than that of insoluble protein. However, the contribution of soluble protein (including peptides) can be significant (Chen et al, 1987). An odd feature of the Cornell model is that although outflow of peptides is represented (Russell et al, 1992), it is not added to the total NAN flow (Sniffen et al, 1992) or AA flow (O'Connor et al, 1993). In the model of Lescoat and Sauvant (1995), the outflow of the different groups of $A A$ was related to the feed $A A$ composition and the escape of soluble and insoluble $\mathrm{N}$ fractions. Evaluation of the updated Cornell model showed $\mathrm{R}^{2}$ between 0.81 and 0.90 for individual $A A$, but there was a clear underprediction of duodenal $A A$ flows for observations with lactating dairy cattle, and overprediction for observations with nonlactating cattle. In view of the clustering of data in these two groups, high $\mathrm{R}^{2}$ values can be misleading and analysis of each individual group would likely yield less favourable results (Glantz and Slinker, 1990). These considerations should also be taken into account in the evaluation of Lescoat and Sauvant (1995), who reported $R^{2}$ of 0.98 and 0.95 for lysine and methionine outflow, respectively. The root MSPE can give more information, and this was $29 \%$ and $22 \%$ for lysine and methionine outflow, respectively, without any apparent bias.

\section{Outflow of substrates}

The removal of undegraded feed substrates and microbial matter has long been recognized as a major process involved in the control of feed intake, the amount of feed degraded and the efficiency of synthesis of microbial matter. Although main aspects of passage are qualitatively understood, quantitative knowledge of a number of key processes is limited (Faichney et al, 1989). This lack of knowledge is reflected in the representation of outflow from the rumen in the whole rumen function models, which is often much less detailed and has a far higher empirical content than fermentation and microbial synthesis processes. However, when sensitivity analyses of rumen models were reported, model results were invariably highly sensitive to the value of passage rates, and the need to specify these parameters with reasonable accuracy was 
emphasized (Beever et al, 1981; Baldwin et al, 1987b; Neal et al, 1992; Dijkstra, 1994a).

The effects of particle size on passage have been described in numerous papers, and generally the probability of passage is inversely related to particle size (Faichney et al, 1989). More recently, the effects of particle functional specific gravity have been described (Lechner-Doll et al, 1991; Kaske et al, 1992). The role of rumen liquid in the passage of material is not completely clear. Particles must leave the rumen in liquid suspension, and formation and function of the filter-bed of rumen digesta mass is affected by rumen liquid volume (Owens and Goetsch, 1986). Very small particles (passing a sieve of mesh 150 $\mu \mathrm{m}$ ) behave like solutes, but only a proportion of them flow in the fluid phase because many are trapped in the filter-bed of rumen digesta mass (Faichney, 1986). In most rumen models, passage of material is assumed to be partly with the fluid phase and partly with the solid phase. The solid phase outflow is sometimes further distinguished in concentrate and roughage particles passage. While in a number of rumen models no guidance to specification of fluid and particulate passage rates is given, in other models regression equations are used to relate the fractional passage rates to factors including dry matter intake (DMI) level and dietary proportions of concentrate and roughage. In whole rumen function models of cattle, Dijkstra et al (1992) and Dijkstra (1994a) use the regression equations reported by Owens and Goetsch (1986) to estimate fractional fluid and particle passage rates; Lescoat and Sauvant (1995) apply similar equations, derived by Sauvant and Archimede (1989). Although these regression equations are based on large datasets, the accuracy is rather low, and when compared to each other, considerable differences in predicted passage rate values exist (Figure 2). The Cornell model computes fractional particle passage rates using regression equations described by Chalupa et al (1991), which in addition to DMI level and proportion of roughage and concentrate in the diet account for particle size effects. Strangely enough, in this model soluble sugars and organic acids are assumed to be washed out with the particles (Sniffen et al, 1992), whilst (soluble) peptides are passed out of the rumen at the fluid dilution rate (Russell et al, 1992), and no guidance is given to determine the fractional fluid passage rate.

Of even more significance than the low predictability of regression equations to estimate passage rates, is the fact that this empirical approach largely ignores the mechanisms of fluid and particle passage rate, as well as their interactions with degradation through rumination and microbial activity. Sutherland (1987) depicted a mathematical approach to represent the relationship between the probability of particles escaping from, and the distribution of particles within the rumen. In whole rumen function models, the model of Baldwin et al (1987b) provide some description of particle dynamics. In this model, large and small particles were distinguished. Large particles were assumed not to be washed out or degraded, but only to be subjected to comminution, and the single outflow is to the small particle pool. Bannink and De Visser (1996) showed that removal of the mechanism of particle dynamics in the model of Baldwin et al (1987b) did severely affect simulated substrate pool sizes, but hardly affected simulated substrate outflow. Thus, simulated pool sizes are strongly dependent on the presence of a delay in substrate availability. However, these results were obtained with a continuous feed input and it was assumed that fractional rates of passage were constant throughout the day. The latter assumption is probably not valid, as Okine and Mathison (1991) observed differences in fractional passage rates before and during feeding. Besides, the diurnal variation in size of carbohydrate and $N$ pools can be of importance, particularly when asynchronous diets are fed discontinuously to ruminants. The topic of non-steady state situations has not received much attention in rumen models. In the models of Baldwin et al (1977, 1987b), simulation results of discontinuous feeding regimes were judged to be realistic, but no comparison with specific data were made. France et al (1982) obtained reasonable agreement between rumen model output and data on sheep fed different diets frequently, but considerable discrepancies occurred when discontinuous feeding patterns were simulated. In conclusion, the representation of outflow from the rumen requires a more mechanistic approach, which should adequately cover continuous as well as discontinuous feeding regimes. 

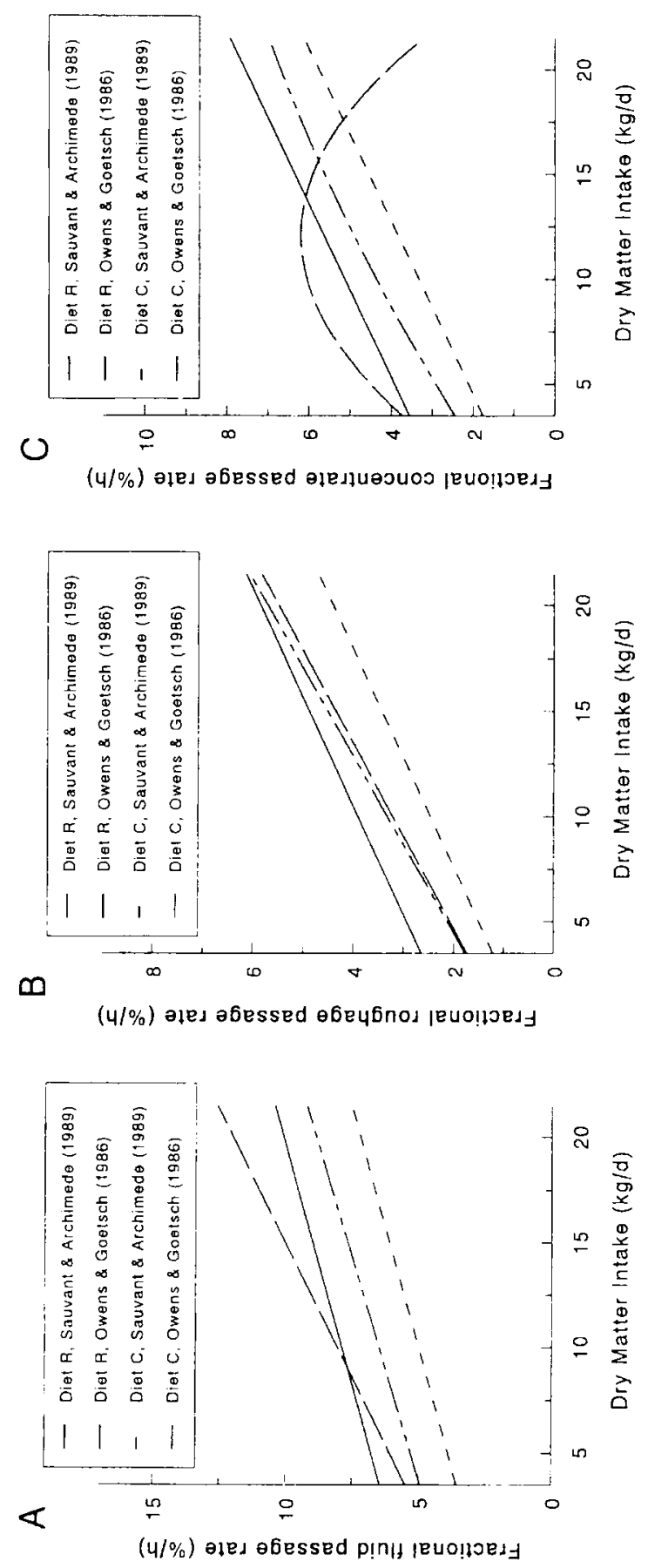

동 웅 ma 뜬 可

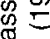
잉 \% 동 흔 음 은 赵 这 띤 $\widehat{0}$ 융 赵 등 을 융 뜸 을 ᄃ

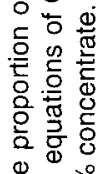
똔 옹ㅇํㅇ 익 웡 西 등 잉

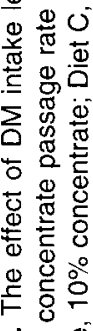
ง 용 혼흔 


\section{Microbial metabolism}

The rumen microbial ecosystem is a complex and dynamic community in which bacteria, protozoa, fungi, mycoplasmas and bacteriophages are present. The metabolic activity of the microbial population is the major determinant of rumen fermentation. Beever (1984) and Sauvant (1988) drew attention to inadequacies in current representations, and indicated several specific areas of improvement, some of which have been reconsidered in recent whole rumen function models. Details on mathematical representation of microbial interactions in the rumen can be found in a recent review (Dijkstra and France, 1995c).

Many rumen microbial species are able to ferment only a limited number of compounds. Such differences in substrate utilization are generally recognized, but to date only limited attention has been given to explicit representation of the different microbial groups. Baldwin et al (1977), Black et al (1981), France et al (1982), Baldwin et al (1987b), and Danfær (1990) represented only one microbial pool. Russell et al (1992), Dijkstra et al (1992) and Lescoat and Sauvant (1995) represent two groups of microbes, one group using SC and the other NSC as major source of energy. Three microbial groups were distinguished in the models of Baldwin et al (1970) and Dijkstra (1994a), whilst Reichl and Baldwin (1975) represented eight microbial groups in order to examine interrelationships among species. There are two reasons for the limited attention given to represent different microbial groups in rumen models explicitly. Firstly, the level of organization of rumen models which have the objective to predict nutrient supply, requires considerable simplifications of the complex microbial ecosystem in the rumen. Yet representation of the microbial ecosystem as a single entity might not suffice. This is particularly so in order to accurately predict the type of VFA produced (see next section), and to avoid undesired interactions among nutrients. For example, Baldwin et al (1987b) had to include separate equations for microbes digesting starch from those digesting fibre to avoid such interactions. Secondly, problems were encountered in developing research models designed to examine the roles of different microbial groups. In a large number of solutions of the Reichl and Baldwin model
(1975), up to four microbial groups were not represented (i.e. simulated extinction of microbial groups), and the model suggested rumen microflora much simpler than the real rumen microflora (Reichl and Baldwin, 1976). Dijkstra (1994a) only obtained biologically realistic coexistence of populations when autoinhibition effects were included in the model.

In most whole rumen function models, metabolic activities of bacteria are represented, whilst those of fungi and protozoa are not represented at all, or in very simple manner. In general, high fibre diets favour the development of fungi in the rumen and the most likely role for rumen fungi is to participate in primary colonization of plant cell walls (review Trinci et al, 1994). Quantitative knowledge on rumen fungi is scarce. France et al (1990) described a life-cycle model of rumen monocentric fungi, to estimate the particleattached thalli population (which cannot be measured experimentally) from a knowledge of the free swimming zoospore population. In comparison with rumen fungi, there is more knowledge on metabolic activities of rumen protozoa. A number of protozoal activities, including engulfment of microbes (Wallace and McPherson, 1987), inability to utilize ammonia as $N$ source (Coleman, 1986), and selective retention in the rumen (Faichney, 1989), affect key nutritional characteristics. Generally, removal of protozoa from the rumen decreases fibre degradation and ammonia and VFA formation in the rumen, and increases undegraded feed protein and microbial protein flow to the duodenum (Jouany et al, 1988). However, explicit representation of microbial recycling within the rumen in models has received limited attention. Reichl and Baldwin (1976) evaluated effects of engulfment of bacteria by protozoa in their rumen model, and showed significant effects on cell yields and end-products of fermentation in the presence of protozoa. The Cornell model makes an allowance for protozoal predation by decreasing the theoretical maximum growth yield by $20 \%$ (Russell et al, 1992). Obviously, this fixed reduction cannot accommodate the variation in microbial turnover due to protozoal predation (Coleman, 1986). Dijkstra et al (1992) represented engulfment of bacteria by protozoa and lysis of protozoa. In this model, protozoa were represented as a fixed part of the amylolytic microbial pool. Evaluation of the model showed that microbial recycling had to 
be represented more accurately, and in a modified model, protozoa and bacteria were represented in separate pools (Dijkstra, 1994a). This integration of protozoal, bacterial, and dietary characteristics through mathematical representation provided explanations for the different roles of protozoa in rumen fermentation processes (Dijkstra, 1994a; Dijkstra and Tamminga, 1995).

Ruminal micro-organisms derive most of their energy from the fermentation of carbohydrates. The energetic efficiency of microbial growth is influenced by a number of factors, including maintenance requirement, availability of preformed monomers, microbial cell composition, fractional growth rate, and microbial turnover (Hespell and Bryant, 1979). Representation of these factors in rumen models will be described subsequently, except for microbial turnover which has been discussed previously.

The overall use of substrates by growing microbes can be divided into substrate

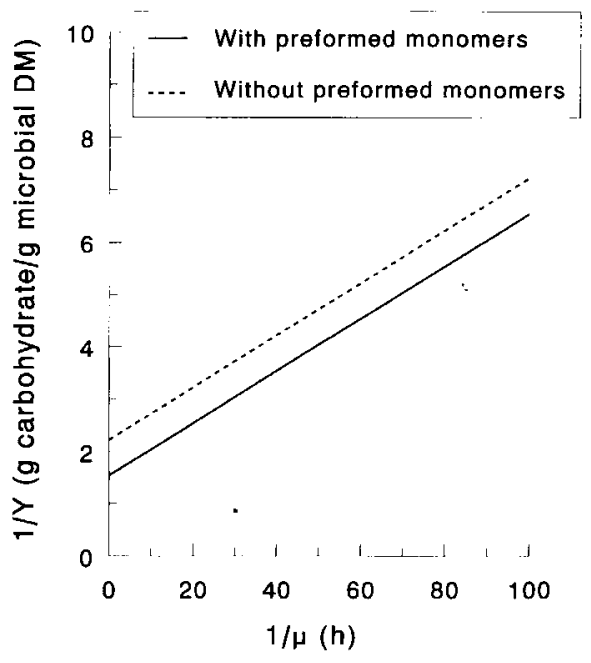

Figure 3. Effect of fractional growth rate $(\mu)$ upon microbial cell yield $(Y)$ according to the Pirt double reciprocal equation. The maintenance requirement for the microbes is $0.05 \mathrm{~g}$ carbohydrates $/ \mathrm{g}$ microbial $\mathrm{DM} / \mathrm{h}$; maximum cell yield is 0.65 and $0.45 \mathrm{~g}$ microbial $\mathrm{DM} / \mathrm{g}$ carbohydrate in presence and absence of preformed monomers, respectively. utilization for maintenance and for mass increase. In most models, maintenance requirements have to be met before growth can occur. Thus, the production of microbial matter is calculated as:

$$
P_{M i}=Y_{\text {max }}\left(U_{S}-M_{e} Q_{M i}\right)
$$

where $P_{M i}(g$ microbial $D M / h)$ is the amount of microbial matter synthesized, $Y_{\max }$ (g microbial $\mathrm{DM} / \mathrm{g}$ substrate) the maximum cell yield, $U_{S}(g$ substrate/h) the utilization of substrate by microbes, $M_{e}$ (g substrate/g microbial $D M / h$ ) the maintenance coefficient, and $Q_{M i}(g$ microbial DM) the microbial biomass in the rumen. This relationship can be rearranged to give the Pirt (1965) double reciprocal equation (Figure 3 ), which is widely used in microbiology:

$1 / Y=M_{e} / \mu+1 / Y_{\max }$

where $Y\left(=P_{M} / U_{S} ; g\right.$ microbial $D M / g$ substrate $)$ is the cell yield and $\mu\left(P_{M i} / Q_{M i} ; / h\right)$ the fractional growth rate. The $M_{e}$ for rumen microbes as derived by Isaacson et al (1975) $(0.05 \mathrm{~g}$ glucose $/ \mathrm{g}$ microbial $\mathrm{DM} / \mathrm{h})$ is frequently applied in rumen models. $M_{e}$ varies with bacterial species and growth conditions (Hespell and Bryant, 1979). In the Cornell model, $\mathrm{M}_{\mathrm{e}}$ for bacteria degrading $\mathrm{SC}$ and NSC is 0.05 and $0.15 \mathrm{~g}$ carbohydrate $/ \mathrm{g}$ microbial $\mathrm{DM} / \mathrm{h}$, respectively. Depending upon dietary conditions, limitations on the availability of nutrients including ammonia, amino acids or peptides can occur, which results in a higher degree of energetic uncoupling and consequently raised $M_{e}$ value (Hespell and Bryant, 1979). This aspect was represented in the models of Baldwin et al (1987b) and Danfær (1990) (but reducing $Y_{\max }$ in stead of increasing $M_{e}$ ), Dijkstra et al (1992), and Dijkstra (1994a).

The absence of preformed monomers, such as amino acids and nucleic acids, can significantly decrease $Y_{\max }$ as well. Hence in most rumen models the variations in carbohydrate or energy requirements as affected by monomer availability have been accounted for, often represented by a Michaelis-Menten type relationship between monomer availability and utilization of carbohydrate or ATP for growth. In the model of Black et al (1981), potential ammonia and amino acid deficiencies are calculated and microbial growth reduced in proportion to the deficiency. This model is unique in that it also reduces microbial growth when sulphur deficiency occurs. With respect to the $\mathrm{N}$ - 
sources available, representations adopted in the Cornell model (Russell et al, 1992) and Lescoat and Sauvant (1995) model are biologically unrealistic. Russell et al (1992) acknowledge that limiting amounts of ammonia will reduce microbial growth yields, but do not include it in the model. Thus, low $\mathrm{N}$ diets can result in low or even negative rumen ammonia levels simulated, while microbial growth is not decreased. Russell et al (1992) recommend examination of simulated ammonia levels and in case of deficiency, suggest addition of nonprotein $N$ to the diet. In the model of Lescoat and Sauvant (1995), the ATP required for growth, once maintenance requirements are met, is calculated from the microbial composition and the proportion of preformed $\mathrm{N}$-substrates captured in relation to $\mathrm{N}$ substrates required. The latter proportion is estimated using an empirical regression equation, with the ratio of microbial protein $\mathrm{N}$ to degraded carbohydrate being the independent variable. Again, there is no representation of growth reduction due to $\mathrm{N}$ deficiency. In evaluation of this model, a (low $N$ ) maize stover diet resulted in a simulated negative ammonia pool, which is biologically impossible.

The chemical composition of microbial matter is another factor which will affect growth yield of microbes. Except for the models of Danfær (1990), Dijkstra et al (1992) and Dijkstra (1994a), in whole rumen function models a fixed chemical composition of the microbial biomass is assumed. The polysaccharide content of microbes is likely the component which varies most with changes in dietary composition and intake level (Storm and Ørskov, 1983). In general, low $N$ diets increase bacterial carbohydrate contents, as also do high concentrate diets compared to all roughage diets (McAllan and Smith, 1977; Storm and Ørskov, 1983). Such variations are included in the models of Dijkstra et al (1992) and Dijkstra (1994a), in that the microbial polysaccharide content varies with the amount of NSC available, in relation to availability of $N$. Microbial protein and polysaccharides can form a significant part of the protein and starch flowing to the duodenum. In view of the attention given to the AA profile of duodenal digesta, in future a more detailed representation of microbial protein composition might become necessary.

Finally, microbial growth efficiency is significantly affected by the growth rate of microbes (Hespell and Bryant, 1979). Higher fractional growth rates result in increased efficiency because less substrate is used for maintenance. In steady state situations and in absence of microbial engulfment and lysis, the fractional growth rate equals the outflow rate. Several compartments in the rumen can be identified, each associated with different fractional outflow rates from the rumen (Cheng and Costerton, 1980). In most rumen models, microbes free in fluid and microbes attached to particles are distinguished, and the fractional outflow rate of each group is assumed to be equal to the fractional fluid and particle outflow rate, respectively. This representation implies that microbes free in fluid have a higher growth efficiency than those attached to particles. In this respect, an increase of the concentrate content of the diet, which will generally decrease the dietary fibre content and as a result increase the relative amount of free living microbes, will raise the overall efficiency. There are a few exceptions to the representation of microbial outflow as outlined above. In the model of Baldwin et al (1987b), the microbes adhering to large particles are assumed not to be washed out, and the attachment or detachment of microbes to large particles calculated from the relative amount of DM in large and small particles and fluid. In the models of Dijkstra et al (1992) and Dijkstra (1994a), protozoa are assumed to leave the rumen at half the fractional particle passage rate, to represent the low outflow of protozoa observed in vivo (Faichney, 1989). In the Cornell model, the fractional growth rate of SC and NSC utilizing bacteria is assumed to be equal to the fractional degradation rate of SC and NSC, respectively (Russell et al, 1992) and this presents some biological problems. The fractional degradation rate of $\mathrm{SC}$ can be as low as $0.01 / \mathrm{h}$ (Sniffen et al, 1992), which is likely to be lower than the lowest particle passage rate observed and survival of the SC degrading bacteria is only possible by attachment to newly ingested particles with a low probability of passage. Equally, the highest degradation rate $(3.5 / \mathrm{h})$ of NSC is obviously much higher than the maximum fractional growth rate rumen microbes can realize (Russell and Baldwin, 1978) and therefore biologically impossible.

Evaluation of outflow of microbial material is limited to the outflow of microbial NAN. The underprediction of microbial NAN outflow on 
low $\mathrm{N}$ diets due to improper representation of $\mathrm{N}$-recycling (Beever et al, 1981; France et al, 1982; Ramangasoavina et al, 1991) has been mentioned previously. Neal et al (1992) evaluated the model of Dijkstra et al (1992) and reported a root MSPE of $37 \%$ of observed microbial NAN outflow (6 experiments, 20 treatments). The Cornell model predicted bacterial NAN outflow with $R^{2}=76 \%(21$ experiments with in total 56 treatments) (O'Connor et al, 1993). In the comparison of several models reported by Ramangasoavina et al (1991), Bannink et al (1993) and Kohn et al (1995), there was no consistent pattern for microbial NAN flow within models between comparisons (table I). In evaluation of microbial NAN outflow, it should be noted that at least some part of the error can be attributed to differences in techniques applied, as indicated by the much higher variation in measurement of microbial NAN flow than total NAN flow (Oldham and Tamminga, 1980).

In conclusion, proper representation of rumen microbial metabolism is essential, the level of representation related to model objectives. Aspects of microbial metabolism which deserve further attention include microbial distribution within the rumen, microbial interactions, and chemical composition of microbial matter.

\section{End products of fermentation}

Major end products of fermentation in the rumen include ammonia, VFA and methane. Aspects of ammonia production and utilization in the rumen were discussed previously (section «Degradation of nitrogen containing substrates» and (Microbial metabolism»). In ruminants, VFA constitute the major source of energy, providing at least $50 \%$ of the total amount of digestible energy (Sutton, 1985). Some models do not include a representation of the total amount of VFA formed (France et al, 1982; Russell et al, 1992; Sniffen et al, 1992) or do not distinguish the type of VFA produced (Baldwin et al, 1977). In the other models, the total amount of VFA produced is calculated from the amount of substrate degraded and not incorporated into microbial mass. Thus, it follows that an incorrect representation of substrate degradation and/or of microbial DM synthesis, will result in incorrect predictions of VFA formed. Baldwin et al (1987b) did not include the depressive effect of $\mathrm{pH}$ upon fibre degradation and overestimated fibre degradation in the rumen for high grain diets. Consequently, total VFA production is overestimated as well, and a MSPE of $13.1 \%$ of observed mean VFA production can be calculated. Neal et al (1992) reported a MSPE of $11 \%$ of observed mean VFA concentration in rumen fluid in evaluating the model of Dijkstra et al (1992). In the model of Lescoat and Sauvant (1995), the ruminal VFA concentration was underestimated (MSPE = $30 \%$ ) and they attributed this to a poor estimation of the absorption of VFA. However, the efficiency of microbial synthesis was seriously overestimated, and this overestimation could explain at least part of the VFA underestimation.

Of the three major VFA, only propionic acid can be used to form glucose in the intermediary metabolism of the ruminant. The glucogenic or lipogenic nature of VFA has been shown to be linked to changes in milk composition (Sutton, 1985), but the effects of differences in VFA ratios on growth and growth composition vary (McRae and Lobley, 1982). The proportions in which the VFA are present in the rumen have been measured frequently and related to dietary characteristics. Baldwin et al (1970) suggested stoichiometric relationships between acetate, propionate, and butyrate, and the degradation of SC, starch, soluble sugars, and protein. These relationships were adopted by Black et al (1981) and Danfær (1990). Murphy et al (1982) estimated stoichiometric yield parameters (acetate, propionate, butyrate, and valerate) by statistical analysis of a large number of in vivo observations. They distinguished cellulose, hemicellulose, starch, sugars, and protein, and a set of stoichiometric parameters was obtained for roughage and concentrate type diets. These stoichiometric parameters were used in the models of Baldwin et al (1987b), Dijkstra et al (1992) and Dijkstra (1994). Lescoat and Sauvant (1995) used empirical regressions between type of VFA formed (acetate, propionate, butyrate) and concentrate proportion of the diet; the branched-chain fatty acids were calculated by difference from $100 \%$. However, all these efforts have largely been unsatisfactory. Beever et al (1981) reported severe underprediction of acetate, and 
overprediction of propionate and butyrate molar proportions. Baldwin et al (1987b) predicted much higher estimates of propionate, and lower estimates of butyrate proportions than observed. A part of this error might be related to the incorrect prediction of $\mathrm{SC}$ degradation. In the updated version, Argyle and Baldwin (1988) included the depressive effect of $\mathrm{pH}$ on fibre degradation and the change in stoichiometric parameters due to variations in $\mathrm{pH}$. Unfortunately, insufficient data prevented challenge of these adjustments to the original model. In evaluation of the Dijkstra et al (1992) model, molar proportions of acetate and valerate were overpredicted, and that of butyrate underpredicted (Neal et al, 1992). Lescoat and Sauvant (1995) reported a satisfactory prediction of acetate molar proportion (MSPE $6 \%$ of observed mean), but unfortunately did not give details on the prediction of the other VFA. Their simple approach has the merit of being rapidly applicable, because it is based solely on the amount of organic matter (OM) fermented and the concentrate proportion of the diet. However, such an approach cannot represent the differences in VFA patterns observed when intake levels are varied (Robinson et al, 1986b) or when different feed ingredients are used (McCarthy et al, 1989). In their comparison of models, Bannink et al (1993) and Kohn et al (1995) reported that VFA patterns were not predicted well. Thus, attempts to predict the supply of VFA based on substrate degradation in the rumen and stoichiometric parameters have not been satisfactory. In a review on production and absorption of VFA in the rumen, Dijkstra (1994b) analyzed the problems and suggested factors to be included in future attempts to predict VFA profiles. Fermentation reactions are controlled by the need to maintain redox balance through reduction and reoxidation of pyridine nucleotides (NAD). Thus, Dijkstra (1994b) recommended that factors involved in the maintenance of the redox balance should be taken into account. These include the composition of the substrate, the substrate availability and rate of depolymerization, and microbial species present.

The formation of methane is related to the production of VFA as well. Methanogenic bacteria in the rumen maintain a very low partial pressure of hydrogen, favouring a maximal flow of carbon towards oxidized VFA end products which have been produced by other rumen microbial species. When methanogenic bacteria are inhibited, molar proportions of propionate will increase (Van Nevel and Demeyer, 1988). A relatively small amount of hydrogen is not used for methane production, but is disposed of via the saturation of LCFA and the synthesis of microbial matter. Only a small number of rumen models represent methane production (Baldwin et al, 1970; Black et al, 1981; Danfær, 1990) and in these representations, relative methane production is reduced when the proportion of propionate produced is increased. No evaluation of methane production is presented in these models. However, the close relationship between methane production and VFA profile implies that systematic errors in VFA prediction will give rise to unsatisfactory predictions of methane production as well. Thus, the thoughts on prediction of the type of VFA produced will be applicable to the prediction of methane production as well. In conclusion, the representation in whole rumen function models of the type of VFA produced needs to be improved and future attempts should include provisions for the effect of amount and rate of degradation of substrate and microbial species preferences on type of VFA produced.

\section{Conclusion}

This paper has attempted to highlight the representation of various aspects of rumen fermentation processes in relation to current knowledge. Modelling of whole rumen function was initiated by Baldwin et al (1970) and has advanced greatly over the last few decades. The whole rumen function models provide a framework to integrate knowledge on various rumen fermentation features, and to predict the supply of nutrients to the ruminant. A number of issues related to rumen modelling require further research. These issues include the simulation of discontinuous feeding regimes and the representation of outflow of material from the rumen, microbial distribution within the rumen, amino acid composition of undegraded feed and microbial matter, interactions between microbes, and the factors determining the VFA profile. 


\section{Literature cited}

Argyle JL, Baldwin RL (1988) Modeling of rumen water kinetics and effects of rumen $\mathrm{pH}$ changes. J Dairy Sci 71,1178-1188.

Baldwin RL, Lucas HL, Cabrera R (1970) Energetic relationships in the formation and utilization of fermentation end-products. In: Physiology of digestion and metabolism in the ruminant (AT Phillipson, EF Annison, DG Armstrong, CC Balch, RS Comline, RS Hardy, PN Hobson, RD Keynes, eds) Oriel Press, Newcastle-upon-Tyne, 319-334

Baldwin RL, Koong LJ, Ulyatt MJ (1977) A dynamic model of ruminant digestion for evaluation of factors affecting nutritive value. Agric Syst 2, 255-288

Baldwin RL, France J, Gill M (1987a) Metabolism of the lactating cow. I. Animal elements of a mechanistic model. J Dairy Res 54,77-105

Baldwin RL, Thornley JHM, Beever DE (1987b) Metabolism of the lactating cow. II. Digestive elements of a mechanistic model. J Dairy Res 54,107-131

Bannink A, De Visser H (1996) Comparison of mechanistic rumen models on mathematical formulation of extramicrobial and microbial processes. J Dairy Sci in press

Bannink A, De Visser H, Van Vuuren AM (1993) Comparison of mechanistic models. II. Validation of the Baldwin. Danfær, and Dijkstra model. IVVO-DLO, Lelystad

Bauchart D, Legay-Carmier F, Doreau M, Gaillard B (1990) Lipid metabolism of liquid-associated and solid-adherent bacteria in rumen contents of dairy cows offered lipid-supplemented diets. $\mathrm{Br} J$ Nutr 63,563-578

Beever DE (1984) Some problems of representing nitrogen metabolism in mathematical models of rumen function. In: Modelling ruminant digestion and metabolism ( $\mathrm{RL}$ Baldwin, $\mathrm{AC}$ Bywater, eds) University of California, Davis, 54-58

Beever DE, Black JL, Faichney GJ (1981) Simulation of the effects of rumen function on the flow of nutrients from the stomach of sheep: part 2 assessment of computer predictions. Agric Syst 6, 221-241

Bibby J, Toutenburg H (1977) Prediction and improved estimation in linear models. John Wiley and Sons, London

Black JL, Beever DE, Faichney GJ, Howarth BR, Graham N McC (1981) Simulation of the effects of rumen function on the flow of nutrients from the stomach of sheep: part 1 -description of a computer program. Agric Syst 6,195-219

Boston RC, Ferguson JD, Kohn RA, Black JL (1995) Model testing and evaluation. In: Proceedings of the IVth international workshop on modelling nutrient utilisation in farm animals (A Danfær, $\mathrm{P}$ Lescoat, eds) National Institute of Animal Science, Foulum, 25-34

Chalupa W, Sniffen CJ, Fox DG, Van Soest PJ (1991) Model generated protein degradation nutrition information. In: Proceedings of the Cornell Nutrition Conference of Feed manufacturers, Cornell University Press, Ithaca, 44-51

Chen G, Sniffen CJ, Russell JB (1987) Concentration and estimated flow of peptides from the rumen of dairy cattle: effects of protein quantity, protein solubility, and feeding frequency. I Dairy Sci 70 , 983-992

Cheng K-J, Costerton JW (1980) Adherent rumen bacteria - their role in digestion of plant material, urea and epithelial cells. In: Digestive physiology and metabolism in ruminants ( $Y$ Ruckebusch, $P$ Thivend, eds) MTP Press, Lancaster, 227-250

Chesson A (1988) Lignin-polysaccharide complexes of the plant cell wall and their effect on microbial degradation in the rumen. Anim Feed $\mathrm{Sci}$ Technol 21, 219-228

Clapperton JL, Czerkawski JW (1969) Methane production and soluble carbohydrates in the rumen of sheep in relation to the time of feeding and the effects of short-term intraruminal infusions of unsaturated fatty acids. Br J Nutr 23 , 813-826

Clark JH, Klusmeyer TH, Cameron MR (1992) Microbial protein synthesis and flows of nitrogen fractions to the duodenum of dairy cows. J Dairy Sci 75, 2304-2323

Cockburn JE, Williams AP (1984) The simultaneous estimation of the amounts of protozoal, bacterial and dietary $\mathrm{N}$ entering the duodenum of steers. BrJ Nutr 51, 111-132

Coleman GS (1986) The metabolism of rumen ciliate protozoa. FEMS Microbiol Rev 39, 321-344

Czerkawski JW (1976) Chemical composition of microbial matter in the rumen. $J$ Sci Food Agric $27,621-632$

Danfær A (1990) A dynamic model of nutrient digestion and metabolism in lactating dairy cows. PhD thesis, National Institute of Animal Science, Foulum

DePeters EJ, Taylor SJ (1985) Effects of feeding corn or barley on composition of milk and diet digestibility. J Dairy Sci 68, 2027-2032

Dijkstra J (1994a) Simulation of the dynamics of protozoa in the rumen. $B r J$ Nutr 72, 679-699

Dijkstra $J(1994 b)$ Production and absorption of volatile fatty acids in the rumen. Livest Prod Sci 39, 61-69

Dijkstra J, France J (1995a) Modelling and methodology in animal science. In: Proceedings of the IVth international workshop on modelling 
nutrient utilisation in farm animals (A Danfær, $\mathrm{P}$ Lescoat, eds) National Institute of Animal Science, Foulum, 9-18

Dijkstra J, France J (1995b) Mathematical integration of starch degradation and outflow in the rumen. In: Abstracts of the SCl Symposium on Carbohydrates in Feeds for Ruminants, 28 February 1995, London

Dijkstra J, France J (1995c) Modelling interactions among micro-organisms in the reticulo-rumen. $\mathrm{ln}$ : Proceedings 7 th international Symposium on Microbial Ecology (MT Martins, ed) in press

Dijkstra J, Tamminga $S$ (1995) Simulation of the effects of diet on the contribution of rumen protozoa to degradation of fibre in the rumen. $\mathrm{Br}$ J Nutr 74, 617-634

Dijkstra J, Neal HDStC, Beever DE, France J (1992) Simulation of nutrient digestion, absorption and outflow in the rumen: model description. J Nutr 122, 2239-2256

Emmans GC (1995) Models and the iterative process of developing and testing hypotheses. In: Proceedings of the $\mathrm{N}$ th international workshop on modelling nutrient utilisation in farm animals (A Danfær, P Lescoat, eds) National Institute of Animal Science, Foulum, 19-24

Erdman RA (1988) Dietary buffering requirements of the lactating dairy cow: a review. $J$ Dairy Sci 71 , 3246-3266

Faichney GJ (1986) The kinetics of particulate matter in the rumen. In: Control of digestion and metabolism in ruminants (LP Milligan, WL Grovum, A Dobson, eds) Prentice-Hall, Englewood Cliffs, 173-195

Faichney GJ (1989) Mean retention time and intraruminal degradation of rumen protozoa. Proc Nutr Soc Aust 14, 135

Faichney GJ, Poncet C, Boston RC (1989) Passage of internal and external markers of particulate matter through the rumen of sheep. Reprod Nutr Develop 29, 325-337

France J, Thornley JHM (1984) Mathematical models in agriculture. Butterworths, London

France J, Thornley JHM, Beever DE (1982) A mathematical model of the rumen. $J$ Agric Sci (Camb) 99, 343-353

France J, Theodorou MK, Davies D (1990) Use of zoospore concentrations and life cycle parameters in determining the population of anaerobic fungi in the rumen ecosystem. $J$ Theoret Biol 147, 413-422

Glantz SA, Slinker BK (1990) Primer of applied regression and analysis of variance. McGraw-Hill Inc, New York

Harfoot CG (1981) Lipid metabolism in the rumen. In: Lipid metabolism in ruminant animals (WW Christie ,ed) Pergamom Press, Oxford, 21-55
Hespell RB, Bryant MP (1979) Efficiency of rumen microbial growth: influence of some theoretical

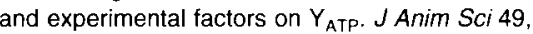
1640-1659

Jouany JP, Demeyer DI, Grain J (1988) Effect of defaunating the rumen. Anim Feed Sci Technol 21, 229-265

Kaske M, Hatiboglu S, Von Engelhardt W (1992) The influence of density and size of particles on rumination and passage from the reticulo-rumen of sheep. Br J Nutr 67, 235-244

Kohn RA, Boston RC, Ferguson JD, Chalupa W (1995) The integration and comparison of dairy cow models. In: Proceedings of the IVth international workshop on modelling nutrient utilisation in farm animals (A Danfær, P Lescoat, eds) National Institute of Animal Science, Foulum, 117-128

Lechner-Doll M, Kaske M, Von Engelhardt W (1991) Factors affecting the mean retention time of particles in the forestomach of ruminants and camelids. In: Physiological aspects of digestion and metabolism in ruminants ( $T$ Tsuda, $Y$ Sasaki, R. Kawashima, eds) Academic Press Inc., Tokyo, 455-482

Lescoat P, Sauvant D (1995) Development of a mechanistic model for rumen digestion validated using the duodenal flow of amino acids. Reprod Nutr Develop 35, 45-70

MacRae JC, Lobley GE (1982) Some factors which influence thermal energy losses during the metabolism of ruminants. Livest Prod Sci 9, 447456.

Maeng WJ, Van Nevel CJ, Baldwin RL, Morris JG (1976) Rumen microbial growth rates and yields: effect of amino acids and protein. J Dairy Sci 59 , 68-79

Mazanov A, Nolan JV (1976) Simulation of the dynamics of nitrogen metabolism in sheep. $\mathrm{Br} J$ Nutr 35, 149-174

McAllan AB, Smith RH (1977) Some effects of variation in carbohydrate and nitrogen intakes on the chemical composition of mixed rumen bacteria from young steers. Br J Nutr 37, 55-65

McAllister TA, Cheng KJ, Rode LM, Buchanan-Smith JG (1990) Use of formaldehyde to regulate digestion of barley starch. Can J Anim Sci 70 581-589

McCarthy RD, Klusmeyer TH, Vicini JL, Clark JH, Nelson DR (1989) Effects of source of protein and carbohydrate on ruminal fermentation and passage of nutrients to the small intestine of lactating cows. J Dairy Sci 72, 2002-2016

Mertens DR (1977) Dietary fiber components: relationship to the rate and extent of ruminal digestion. Fed Proc 36, 187-192 
Murphy MR, Baldwin RL, Koong LJ (1982) Estimation of stoichiometric parameters for rumen fermentation of roughage and concentrate diets. J Anim Sci 55, 411-421

Murphy MR, Baldwin RL, Ulyatt MJ, Koong LJ (1983) A quantitative analysis of rumination patterns. J Anim Sci 56, 1236-1240

Murphy MR, Baldwin RL, Ulyatt MJ (1986) An update of a dynamic model of rumen fermentation. $J$ Anim Sci 62, 1412-1422

Neal HDStC, Dijkstra J, Gill M (1992) Simulation of nutrient digestion, absorption and outflow in the rumen: model evaluation. J Nutr 122, 2257-2272

Nocek JE, Tamminga S (1991) Site of digestion of starch in the gastrointestinal tract of dairy cows and its effect on milk yield and composition. $\checkmark$ Dairy Sci 74, 3598-3629

O'Connor JD, Sniffen CJ, Fox DG, Chalupa W (1993) A net carbohydrate and protein system for evaluating cattle diets: IV. Predicting amino acid adequacy. J Anim Sci 70, 3551-3561

Okine EK, Mathison GW (1991) Reticular contraction attributes and passage of digesta from the ruminoreticulum in cattle fed roughage diets. $J$ Anim Sci 69, 2177-2186

Oldham JD, Tamminga $S(1980)$ Amino acid utilization by dairy cows. 1 . Methods of varying amino acid supply. Livest Prod Sci 7, 437-452

Oldham JD (1984) Protein-energy interrelationships in dairy cows. J Dairy Sci 67, 1090-1114

Owens FN, Goetsch AL (1986) Digesta passage and microbial protein synthesis. In: Control of digestion and metabolism in ruminants (LP Milligan, WL Grovum, A Dobson, eds) PrenticeHall, Englewood Cliffs, 196-223

Pirt SJ (1965) The maintenance energy of bacteria in growing cultures. Proc Royal So. London Series B 163, 224-231

Ramangasoavina B, Sauvant D, Robert JC (1991) The relative supply of degradable nitrogen for microbes as a factor of bias for rumen models. In: Protein metabolism and nutrition, Vol. 2 (BO Eggum, S Boisen, C Borsting, A Danfær, T Hvelplund, eds) National Institute of Animal Science, Foulum, 355-357

Reichl JR, Baldwin RL (1975) Rumen modelling: rumen input-output balance models. J Dairy $\mathrm{Sci}$ $58,879-890$

Reichl JR, Baldwin RL (1976) A rumen linear programming model for evaluation of concepts of rumen microbial function. J Dairy Sci 59, 439-454

Robinson PH, Fadel JG, Tamminga S (1986). Evaluation of mathematical models to describe neutral detergent residue in terms of its susceptibility to degradation in the rumen. Anim Feed Sci Technol 15, 249-271

Robinson PH, Tamminga S, Van Vuuren AM (1986b) Influence of declining level of feed intake and varying the proportion of starch in the concentrate on rumen fermentation in dairy cows. Livest Prod Sci 15, 173-189

Russell JB, Baldwin RL (1978) Substrate preferences in rumen bacteria: evidence of catabolite regulatory mechanism. App/ Environ Microbiol $36,319-329$

Russell JB, Sniffen CJ, Van Soest PJ (1983) Effect of carbohydrate limitation on degradation and utilization of casein by mixed rumen bacteria. $J$ Dairy Sci 66, 763-775

Russell JB, O'Connor JD, Fox DG, Van Soest PJ, Sniffen CJ (1992) A net carbohydrate and protein system for evaluating cattle diets: I. Ruminal fermentation. J Anim Sci 70, 3551-3561

Sauvant D (1988) Modelling digestion in the rumen. Reprod Nutr Develop 28, 33-58

Sauvant D, Archimede $\mathrm{H}$ (1989) The prediction of the digesta passage rate in ruminants. INRA-INAPG, Paris.

Sauvant D, Dijkstra J, Mertens D (1995) Optimization of ruminal digestion: a modelling approach. In: Recent developments in the nutrition of herbivores (M Journet, E Grenet, M-H Farce, M Thériez, C Demarquilly, eds.) INRA Editions, Paris, 143-165

Sniffen CJ, O'Connor JD, Van Soest PJ, Fox DG, Russell JB (1992) A net carbohydrate and protein system for evaluating cattle diets: II. Carbohydrate and protein availability. $J$ Anim Sci 70 , 3562-3577

Storm E, Orskov ER (1983) The nutritive value of rumen micro-organisms in ruminants. I. Largescale isolation and chemical composition of rumen micro-organisms. Br J Nutr 50, 463-470

Sutherland TM (1987) Particle separation in the forestomachs of sheep. In: Aspects of digestive physiology in ruminants (A Dobson, MJ Dobson, eds.) Comstock Publishing Associates, Ithaca , London, 43-73

Sutton JD (1985) Digestion and absorption of energy substrates in the lactating cow. J Dairy Sci 68 , 3376-3393

Thornley JHM, Johnson IR (†990) Plant and crop modelling. A mathematical approach to plant and crop physiology. Clarendon Press, Oxford

Trinci APJ, Davies DR, Gull K, Lawrence MI, Nielsen BB, Rickers A, Theodorou MK (1994) Anaerobic fungi in herbivorous animals. Mycological Research 98, 129-152

Van Nevel CJ, Demeyer DI (1988) Manipulation of rumen fermentation. In: The rumen microbial ecosystem (PN Hobson, ed) Elsevier Science Publishers, London, 387-444

Wallace RJ, McPherson CA (1987) Factors affecting breakdown of bacterial protein in rumen fluid. $\mathrm{Br}$ J Nutr 58,313-323. 